\title{
The interaction between (o-acetylphenyl)ferrocene and metal ions
}

\author{
Shoko Yamamoto and Yutaka Okada* \\ Department of Applied Chemistry, Ritsumeikan University, 1-1-1 Nojihigashi, Kusatsu, \\ Shiga 525-8577, Japan
}

(Received September 23, 2016; Revised October 15, 2016; Accepted October 28, 2016)

\begin{abstract}
The oxidation reaction of ferrocene derivatives is important because of its biological applications. The reactivity is affected by metal ions. However, it is not clear how to interact the metal ions with the ferrocenes. In this paper, the oxidation reactivity of (o-acetylphenyl)ferrocene was investigated in the view of solvent effect and the addition effect of salicylic acid. Furthermore, the measurement of the relaxation time was carried out. As a result, $\mathrm{Al}^{3+}$ would strongly interact with (o-acetylphenyl)ferrocene so that prevent the mobility of the acetyl group.
\end{abstract}

Keywords: Ferrocene derivatives; metal ion; oxidation reaction; solvent effect; relaxation time; salicylic acid. (C) 2017 ACG Publications. All rights reserved.

\section{Introduction}

The ferrocene iron is Fe(II), while the ferrocenium iron is Fe(III). The oxidation of ferrocenes to ferrocenium ion ${ }^{1}$ is very important for biological applications. ${ }^{2}$ For example, this can be applied to the antitumor activity ${ }^{3,4}$ and the synthesis of bio-related compounds. ${ }^{5-9}$ Ferrocene is very stable in air, so that the oxidation from $\mathrm{Fe}$ (II) to $\mathrm{Fe}$ (III) is difficult. However, under acidic conditions, ferrocene is readily oxidized to the ferrocenium ion ${ }^{1}$. The oxidation reaction of ferrocene derivatives by air under acidic conditions has been investigated by several researchers. ${ }^{10,11}$ The reaction mechanism was considered as follows ${ }^{11}$ : the ferrocenonium ion ${ }^{1}$ forms by coordination of a proton followed by the loss of a hydrogen atom by the attack of oxygen (Scheme 1).

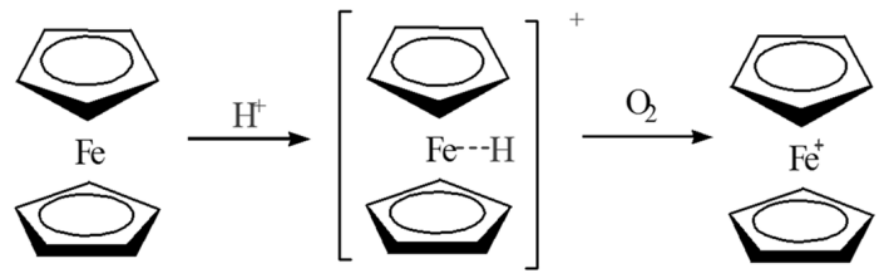

Scheme 1. Oxidation mechanism of ferrocene under acidic conditions

In a previous paper, ${ }^{12}$ we have shown that the oxidation reaction of (o-acetylphenyl)ferrocene is accelerated by the formation of a chelate-ring containing a proton. However, the oxidation reactivity in the presence of several metal salts was suppressed. This result showed that (oacetylphenyl)ferrocene forms a chelate with some metal ions. In the chelate, the carbonyl oxygen and

* Corresponding author: E mail: ygvictor@sk.ritsumei.ac.jp 
iron atom would be the coordination points to the metal ions. In this paper, we discuss the interaction between ( $o$-acetylphenyl)ferrocene and metal ions in more detail. For this purpose, the solvent effect on the oxidation reaction and the addition effect of salicylic acid are discussed. Also, a NMR relaxation time study was carried out to prove the mobility of the acetyl proton.

\section{Experimental}

\subsection{Syntheses} procedure. $^{15}$

(Acetylphenyl)ferrocenes were synthesized from ferrocene based on a previously reported

\subsection{Measurements of oxidation reactivity}

The oxidation reactions were carried out using trichloroacetic acid as the catalyst at $40^{\circ} \mathrm{C}$. The solvents included ethanol:dioxane $(9: 1(\mathrm{v} / \mathrm{v}))$, and 1,2-dichloroethane. The metal salts included $\mathrm{Mg}\left(\mathrm{ClO}_{4}\right)_{2}, \mathrm{Sr}\left(\mathrm{ClO}_{4}\right)_{2}, \mathrm{Y}\left(\mathrm{ClO}_{4}\right)_{3}, \mathrm{Al}\left(\mathrm{ClO}_{4}\right)_{3}$ and $\mathrm{Ca}\left(\mathrm{ClO}_{4}\right)_{2}$. The conversion was measured by analyzing the amounts of the unreacted ferrocenes by HPLC. The rate constants were calculated as a pseudo-first order reaction regarding the ferrocene derivative.

\subsection{Measurements of relaxation time}

(Acetylphenyl)ferrocenes $(0.01 \mathrm{mmol})$ and the metal salt $(0.01 \mathrm{mmol})$ were dissolved in $\mathrm{CD}_{3} \mathrm{CN}$. For the solution, the relaxation time of the proton was measured by the inversion-recovery method using a JEOL ECS-400 spectrometer.

\section{Results \& discussion}

\subsection{The solvent effect}

The rate constants of the reactions in the presence of the metal salts are shown in Table 1. By these metal ions, the rate constants in ethanol:dioxane are suppressed as mentioned in the previous paper. ${ }^{12}$ However, in 1,2-dichloroethane, the metal ions except for the $\mathrm{Al}^{3+}$ brought about the increase of the rate constants. These results indicated that the approach of the proton to the Fe of ferrocene of ferrocene becomes more difficult in ethanol:dioxane by the existence of the metal ions. In contrast, in 1,2-dichloroethane, the approach is easily carried out even in the presence of metal ions. As mentioned in the previous paper, ${ }^{12}$ the $o$-derivative may form a chelate ring with a metal ion. In ethanol:dioxane, the proton is solvated by ethanol, so that it becomes sterically bulky. ${ }^{13}$ Therefore, the approach to the Fe by such a bulky proton is hindered, specifically for the chelated $o$-derivative with a metal ion. Thus, the oxidation reaction was suppressed in the presence of metal ions. The factor that controlls the oxidation rate was the valence, " $\mathrm{M}^{2+}>\mathrm{M}^{3+\text { ". }}$. As shown in Table 1 , the order of the oxidation reactivity in 1,2-dichloroethane is " $\mathrm{Mg}^{2+}, \mathrm{Sr}^{2+}, \mathrm{Y}^{3+}, \mathrm{Ca}^{2+}>$ none $>\mathrm{Al}^{3+}$ ". In the case of 1,2-dichloroethane, the proton is less solvated than in ethanol:dioxane. Therefore, it can easily approach to the Fe even in the presence of the chelate-formed $o$-derivative. The main controlling factor is the ionic radius. For example, the rate constant for $\mathrm{Al}^{3+}$ was lower, because the radius of $\mathrm{Al}^{3+}$ is low. The reason why the reactivity with $\mathrm{Al}^{3+}$ was less than that in the absence of metal ions is discussed as follows: $\mathrm{Al}^{3+}$ forms a strong chelate and exists close to the Fe of ferrocene (Scheme 2a). The approach of the proton on the $\mathrm{Fe}$ is disturbed. This disturbance would bring about a decrease in the oxidation rate. In the case of the metal ions, except for $\mathrm{Al}^{3+}$, the metal ions coordinate close to the oxygen of the acetyl group in the chelate-ring (Scheme 2b). This suggests that the metal ions except for $\mathrm{Al}^{3+}$ coordinate with the oxygen, and interact weaker with the Fe. Therefore, the Fe would be easily approached by the proton and be easily oxidized. Based on these observations, we concluded that the order of the oxidation reactivity is " $\mathrm{Mg}^{2+}, \mathrm{Sr}^{2+}, \mathrm{Y}^{3+}, \mathrm{Ca}^{2+}>$ none $>\mathrm{Al}^{3+}$ ". In the absence of metal ions, the oxidation reaction takes place more easily. In the previous paper, ${ }^{12}$ the oxidation reaction of the $p$-derivative is accelerated in the presence of the metal ions. By the same reason, in the case of $\mathrm{Mg}^{2+}, \mathrm{Sr}^{2+}, \mathrm{Y}^{3+}, \mathrm{Ca}^{2+}$, 
the oxidation reaction is also accelerated than that with no metal ions. For $\mathrm{Al}^{3+}$, the oxidation reactivity is lower than that with no metal ions. This would be due to the forming of a stronger chelate-ring.
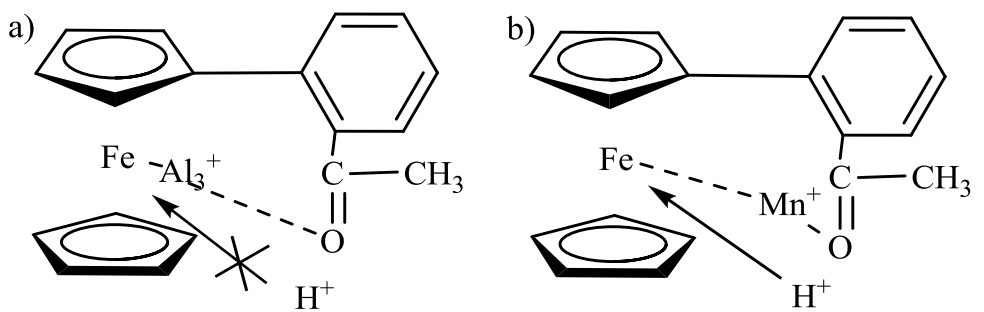

Scheme 2. Plausible coordination of (o-acetylphenyl)ferrocene (a) with $\mathrm{Al}^{3+}$, (b) with metal ions except for $\mathrm{Al}^{3+}$

Table 1. The rate constants of (acetylphenyl)ferrocenes in the presence of metal ions

\begin{tabular}{|c|c|c|c|c|c|c|c|}
\hline & \multirow[b]{2}{*}{ solvent } & \multicolumn{6}{|c|}{$k \times 10^{5} / \mathrm{s} \mathrm{s}^{-1}$} \\
\hline & & none & $\mathbf{M g}^{2+a}$ & $\mathbf{A l}^{3+a}$ & $\mathbf{C a}^{2+a}$ & $\mathbf{S r}^{2+a}$ & $\mathbf{Y}^{3+} \mathrm{a}$ \\
\hline$o$-acetyl & ethanol:dioxane $(9: 1) \mathrm{b}$ & 7.5 & 4.8 & 2.3 & 5.2 & 4.7 & 2.2 \\
\hline$o$-acetyl & 1,2-dichloroethane & 1.5 & 2.0 & 0.75 & 3.0 & 3.0 & 2.5 \\
\hline$p$-acetyl & 1,2-dichloroethane & 1.0 & - & - & - & 2.0 & - \\
\hline
\end{tabular}

a) (acetylphenyl)ferrocenes: metal salt $=1: 1$

b) Ref. 12

\subsection{The relaxation time}

As shown in Table 2, in the presence of metal ions, the relaxation time became shorter than that of no metal ions. On the other hand, for the ( $p$-acetylphenyl)ferrocenes, no noticeable change was observed by the addition of the metal ion. In general, the shortening of the relaxation time indicates that the mobility of the proton decreases. ${ }^{14}$ In this case, the $o$-derivative forms a chelate-ring with the metal ions. Therefore, the mobility of the acetyl group would be reduced. These values of the relaxation time would support the formation of such a chelate-ring.

Table 2. The relaxation time of the acetyl proton in (acetylphenyl) ferrocenes in the presence of metal ions

\begin{tabular}{|c|c|c|c|c|c|c|}
\hline & \multicolumn{6}{|c|}{ relaxation time/s } \\
\hline & none & $\mathrm{bMg}^{2+}$ & ${ }^{b} \mathbf{A l}^{3+}$ & ${ }^{b} \mathrm{Ca}^{2+b}$ & $\mathrm{Sr}^{2+}$ & $\mathbf{Y}^{3+}$ \\
\hline$o$-acetyl & 10.3 & 5.1 & 3.5 & 2.8 & 3.6 & 8.6 \\
\hline$p$-acetyl & 3.1 & - & - & - & - & 3.2 \\
\hline
\end{tabular}

\subsection{The addition effect of salicylic acid}

In the presence of salicylic acid, only the reaction rate with $\mathrm{Mg}^{2+}$ increased, while that with $\mathrm{Al}^{3+}$ was similar. The reactivity with the other metal ions decreased. The order of the reactivity was also the same other than for $\mathrm{Mg}^{2+}$. It is suspected that $\mathrm{Mg}^{2+}$ is more easily trapped by salicylic acid than the (o-acetylphenyl)ferrocene. As a result, (o-acetylphenyl)ferrocene does not form the chelatering, so that it becomes more easily approached by the proton. For $\mathrm{Al}^{3+}$, the reactivity did not change by using salicylic acid. This would be due to forming a stable chelate-ring with both the $(o-$ acetylphenyl)ferrocene and salicylic acid. For the other metal ions, the reactivity decreased by using salicylic acid. In these cases, the salicylic acid would act as a trap reagent of the catalytic proton. These results are summarized by the ion coordination ability of ( $o$-acetylphenyl)ferrocene and salicylic 
acid as follows (Table 3): for $\mathrm{Mg}^{2+}$, " $\left(o\right.$-acetylphenyl)ferrocene < salicylic acid"; for $\mathrm{Al}^{3+}$, " $(o$ acetylphenyl)ferrocene = salicylic acid"; and for the other ions, "(o-acetylphenyl)ferrocene $>$ salicylic acid".

Table 3. The rate constants of (o-acetylphenyl)ferrocene in the presence of salicylic acid

\begin{tabular}{|c|c|c|c|c|c|c|c|}
\hline & \multirow[b]{2}{*}{ additive $^{b}$} & \multicolumn{6}{|c|}{$k \times 10^{5} / \mathrm{s} \mathrm{s}^{-1} \cdot$} \\
\hline & & none & $\mathrm{Mg}^{2+}$ & $\mathbf{A l}^{3+}$ & $\mathrm{Ca}^{2+}$ & $\mathrm{Sr}^{2+}$ & $\mathbf{Y}^{3+}$ \\
\hline$o$-acetyl & none & 1.5 & 2.0 & 0.75 & 3.0 & 3.0 & 2.5 \\
\hline$o$-acetyl & salicylic acid & 1.0 & 3.5 & 0.75 & 1.5 & 2.5 & 1.0 \\
\hline
\end{tabular}

a-in 1,2-dichloroethane

b-(o-acetylphenyl)ferrocenes:metal salt:adduct $=1: 1: 1$

\section{References}

[1] Bitterwolf, T.E.; Ling, A.C. Ferrocenium ion: $\mathrm{Fc}^{+}$, ferrocenonium ion: $[\mathrm{Fc}-\mathrm{H}]^{+}$. Metallocene basicity. II. Reaction of the ferrocenonium cation with molecular oxygen and sulfur dioxide. J.Organomet. Chem. 1972, 40 C29-C3217.

[2] Koepf-Maier, P.; Koepf, H.; Neuse, E. W. Ferrocenium salts-The first antineoplastic iron compounds. Angew. Chem. Int. Ed. Engl. 1984, 23, 456-457.

[3] Georgopoulou, A. S.; Mingos, D. M. P.; White, A. J. P.; Williams, D. J.; Horrocks, B. R.; Houlton, A. Bifunctional ferrocene derivatives for molecular recognition of DNA duplexes. J. Chem. Soc. Dalton Trans. 2000, 2969-2974.

[4] Osella, D.; Ferrali, M.; Zanello, P.; Laschi, F.; Fontani, M.; Nervi, C.; Cavigiolio, G. On the mechanism of the antitumor activity of ferrocenium. Inorg. Chim. Acta. 2000, 306, 42-48.

[5] Zora, M.; Guengoer, E. U. Reaction of ferrocenylcarbene complexes of Cr, Mo and W with alkynes: synthesis of ferrocenylcyclobutenones, ferrocenylfurans and ferrocenylketoesters. Tetrahedron Lett. 2001, 42, 47334735 .

[6] Zora, M.; Yucel, B.; Peynircioglu, N. B. Coupling of ferrocenyl chromium carbene complex with cyclobutenediones. J. Organomet. Chem. 2002, 656, 11-17.

[7] Zora, M.; Yucel, B.; Acikalin, S. Synthesis of ferrocenyl quinones. Tetrahedron Lett. 2003, 44, $2237-2241$.

[8] Zora, M.; Kokturk, M.; Eralp, T. Synthesis of 2-ferrocenylidene-4-cyclopentene-1,3-diones. Tetrahedron 2006, 62, 10344-10351.

[9] Zora, M.; Tumay, T. A.; Bueyuekguengoer, B. Coupling of cyclopropylcarbene-chromium complex with ferrocenyl alkynes: synthesis of 5-ferrocenyl-5-hydroxy-2-cyclopentenones and 4-ferrocenyl-4- cyclopentene1,3-diones. Tetrahedron 2007, 63, 4018-4026.

[10] Muto S.; Kochi H.; Kamiya Y. Oxidation reaction of ferrocene derivatives in acidic solvents. J. Jpn. Petrol. Inst. 1974, 17, 150-153.

[11] Bitterwolf, T. E. ;Ling, A. C. Metallocene basicity: I. Ring tilt and restricted rotation in protonated alkylferrocenes. J. Organomet. Chem. 1972, 40, 205-214.

[12] Okada, Y.; Sasaki. M. The effect of metal salts on the oxidation reaction of (acetylphenyl)ferrocenes. Org. Commun. 2013, 6, 120-124.

[13] Hayashi, T.; Okada, Y. Steric effect of $t$-butyl groups and solvent effect on the oxidation reaction of $t$ butylferrocenes. Bull. Chem. Soc. Jap. 1995, 11, 900-903.

[14] Arimura, T.; Ide, S. ${ }^{1} \mathrm{H}$ NMR relaxation time studies of molecular motions in a 1,3-alternate-shaped calix[4]arene ensemble. J. Oleo. Sci. 2004, 5, 275-278.

[15] Hayashi, T.; Okada, Y. Studies on ferrocene derivatives. I. A conformational study of (substituted phenyl)ferrocenes by the method of proton NMR. Bull. Chem. Soc. Jap. 1987, 2, 208-214.

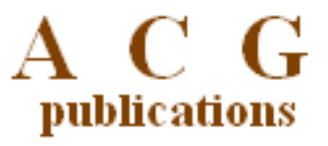

(C) 2017 ACG Publications 